\title{
BENCHMARK NEW PRODUCT DEVELOPMENT PROCESSES USING DEA-BASED MODULARIZED APPROACH
}

\author{
Tzu-An Chiang, Mingchi University of Technology, tachiang@mail.mit.edu.tw \\ Amy J.C. Trappey, National Taipei University of Technology, trappey@ntut.edu.tw \\ and National Tsing Hua University, trappey@ie.nthu.edu.tw \\ Wen-Chih Chen, National Chiao Tung University, wenchih@faculty.nctu.edu.tw
}

\begin{abstract}
Developing new products efficiently complying with resource constraints is a key success factor in today's marketplace. However, unpredictable incidents occur during new product development (NPD) processes, which often cause resources and schedule overruns. Traditional project management tools lack of efficient and effective methods to solve these problems and challenges. This study applies the data envelopment analysis (DEA) concept to develop a novel project planning and management decision support methodology for NPD that can allocate resources economically and respond unexpected delays dynamically. This paper describes a mobile phone NPD case study to demonstrate the real-world application. In the case study, the proposed approach significantly reduces NPD resource spending on the non-critical activities and optimally allocates the resource on the critical path. The result complies with time, budget and resource constraints and provides project managers solid recommendations for NPD execution improvement within a product portfolio.
\end{abstract}

Keywords: New Product Development, Data Envelopment Analysis (DEA), Project Planning and Management

\section{INTRODUCTION}

Introducing new products on time within resource constraints is a key to success in today's competitive market place. Thus, distributed and collaborative product development paradigms are emerged considering time-to-market and cost efficiency for the complexity of modern product design. However, unpredictable incidents usually occur during new product development (NPD) processes, which cause resources and schedule overruns. Conventional project planning methods, estimating time, budgets and resources of NPD activities, are often based on project managers' expertise and subjective judgment. Applying the subjective cost-duration relationship for each activity and the PERT (Program evaluation and review technique)/CPM (Critical path method) technique, the NPD project schedule, budget and the probability of meeting the deadline are obtained. However, the NPD project managers lack objective benchmarking models to gain valuable insights into the relations between resource allocations and activity times in order to support NPD engineers in the best collaborative practices, especially during the planning and execution phase. During the NPD planning phase, the proposed schedule may not satisfy the due day required by customers. Thus, the project managers need to alter the plan accordingly. In addition, during the execution phase, the initially proposed schedule may become infeasible due to the unexpected delay of NPD activities. Therefore, modification of the project plan, while the project is being executed, is needed. However, traditional project management tools cannot provide mechanisms to dynamically modify NPD projects to avoid resources and schedule overruns. This research is to develop a novel project planning and management decision support methodology to optimally allocate resources and dynamically response to unexpected delays. This study develops a benchmarking methodology to optimize a NPD process during its lifecycle. The lifecycle of a NPD process is divided into three phases, i.e., the planning, execution and completion-and-review phases. In the planning and execution phases, this research defines analytical benchmarking models and creates the feedforward and feed-back modification mechanisms to optimize NPD processes. When the process is completed, the relative economical efficiency of the NPD processes within a product portfolio is evaluated and reviewed using data envelopment analysis (DEA) approach. The DEA results provide NPD managers concrete and quantifiable improvement suggestions. In order to demonstrate the real-world application, a mobile-phone development project scenario is used as a case study to illustrate the effectiveness of the methodology.

\section{LITERATURE REVIEW}

Many published papers on NPD management have put forward a wide variety of models for NPD planning and performance evaluation. By using a 
simulation model, Yang and Sum [12] investigate the performance of due date, resource allocation and activity scheduling rules in a multi project environment. The results show when due day nervousness is not mitigated, first in system first served (FISFS) resource allocation rule performs better than the due day sensitive resource allocation rules. Sicotte and Langley [10] examine the efficacy of five types of integration mechanisms for project performance in a sample of $121 \mathrm{R} \& \mathrm{D}$ projects. This study shows the managers adjusted their use of horizontal structures, planning and process specification, and informal leadership to project uncertainty. In addition, integration mechanisms do not enhance performance in context of low uncertainty. In order to identify the key determinants that affect the project performance, artificial neural network (ANN) technique is used to check whether these performance metrics can predict design-build project performance [8]. Vandevoorde and Vanhoucke [11] compare three different methods to forecast the duration of a project. By using real-life project data, they find the planned value rate [1] and the earned duration [7] are unreliable. Instead, the earned schedule method [6] seems to provide reliable results through the project lifecycle. Pillai et al. [9] develop a framework for an integrated performance index encompassing the entire $R \& D$ project lifecycle. The project lifecycle consists of the project selection, execution and implementation phases. The key factors are identified in each phase and integrated through a formula to derive an integrated performance index. According to Bonner et al. [4], early new product development teams and upper management involvement in the setting of operational controls, such as procedures for monitoring the project, was positively associated with project performance. Atuahene-Gima et al. [2] identify that responsive and proactive market orientations have curvilinear effects on product development performance. A responsive market orientation has a U-shaped relationship with NPD project performance. Azaron et al. [3] present a multi-objective model for optimally allocating the resources to the activities within a project. It is assumed that each activity time is an independent random variable with the exponential distribution. Although there are a lot of research efforts on NPD management, few studies concerning NPD process adjustment are available. From a practical perspective, the planning and execution phases of a NPD process often needs to be modified for achieving the goal of a NPD project in an uncertain and changing environment. Hence, NPD project managers need an approach to provide quantitative suggestions for optimizing NPD processes throughout the entire process lifecycle. This research fills the gap to develop decision supporting models and the modification mechanisms to enhance the efficiency of NPD processes.

\section{THE METHODOLOGY FOR NPD PROCESS OPTIMIZATION}

Figure 1 shows the framework of the modularized benchmarking methodology for NPD process optimization. There are includes six modules into the framework, i.e., (1) the process modification, (2) the estimation of project completion time, (3) the resource allocation given most-likely time, (4) the time estimation given resource allocation, (5) the time estimation with added resource allocation, and (6) the relative economical efficiency for the NPD processes within a product portfolio.

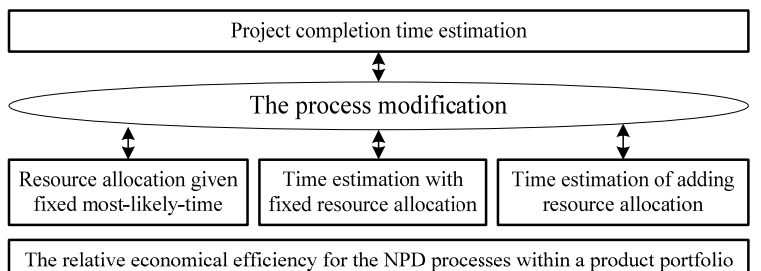

Figure 1. The framework of the benchmarking-based methodology for NPD process optimization.

In the planning phase, the feed-forward modification mechanism (FFMM), first, applies the module of project completion time estimation to calculate the probability of project time set by customer. If the estimation satisfies the customer's requirement, the FFMM, then, employs the resource allocation given most-likely time to benchmark and adjust all resource allocations of activities among the NPD processes. On the other hand, if the time estimation cannot satisfy the customer's requirement, the FFMM utilizes the modules of the time estimation given fixed resource allocation and added resource allocation to reduce the expected NPD process time. During the execution phase, if a certain NPD activity delays, the feed-back modification mechanism (FBMM) is activated to assess whether the subsequent NPD activities need to be modified by applying the time estimation with added resource allocation.

\section{Estimation of Project Completion Time}

In this functional module, the PERT/CPM approach is adopted to calculate the expected value and variance of the NPD completion time and the probability of meeting the specified project deadline. First of all, a project manager defines a "project 
network" diagram based on the logical sequence of NPD activities. Then, the NPD manager and participants jointly define the three time estimates of the optimistic time (o), the most likely time (m) and the pessimistic (worst) time (p) of each activity respectively under different executive conditions. The expected value and variance of a NPD activity time can be obtained by using Equation (1) and Equation (2). This research shortens the expected activity time by adjusting the most likely time.

$$
\begin{gathered}
\mu=\frac{o+4 m+p}{6} \\
\sigma^{2}=\left(\frac{p-o}{6}\right)^{2}
\end{gathered}
$$

In order to calculate the expected value and variance of each path within a project network, all activity times of a NPD process are assumed as statistically independent variables. The expected time of a path are given by summing up the expected activity durations $\left(\mu_{i}\right)$ along the path. And, a path with the largest expected path time, i.e., the expected project completion time $\left(\mu_{P}\right)$, is called the critical path. Furthermore, the variance of a project completion time, i.e., $\sigma_{P}^{2}$, is the sum of variances of the activity times ( $\left.\sigma_{i}^{2}\right)$, on the critical path. According to the central limit theorem, the probability distribution of a sum of NPD activity times on the critical path is approximately normal distribution. If there are more than five activities on the critical path, the distribution of the project completion time yields a reasonable approximation [5]. Hence, the probability of meeting the specified project deadline $\mathrm{d}$ can be obtained using Equation (3).

$$
P(T \leq d)=P\left(Z \leq\left(d-\mu_{P}\right) / \sigma_{P}\right)
$$

\section{The Process Modification}

The NPD process modification is composed of the FFMM and FBMM. Figure 2 displays the FFMM, which is being applied during the planning phase. First, the FFMM forecasts the time performance of a NPD process, i.e., the probability of the NPD project completed on time. If the time performance can satisfy the customer's requirement, the FFMM analyzes the best feasibility of reducing NPD activity resources under the completion time constraint. Hence, the FFMM performs the best resource allocations given most-likely times for activities within a NPD process. On the other hand, if the time performance cannot satisfy the customer's requirement, the FFMM calculates the best feasibility of decreasing the activity times on the critical path without incurring additional resources using the module of time estimate with fixed resource allocation. Once the time performance achieves the requirement, the FFMM applies the module of the resource allocation given most-likely time to analyze the feasibility of decreasing resource allocations of other NPD activities under the process time performance without being influenced.

If the time performance of a NPD process cannot be achieved using the time estimation given resource allocation, the FFMM analyzes the feasibility of increasing resources on the critical path to shorten the expected process completion time. In this case, the FFMM utilizes the time estimation with added resource allocation to assess the time-cost performance of all activities on the critical path. If no feasible solution can be found, the project manager needs to consult with the customer in extending the NPD deadline.

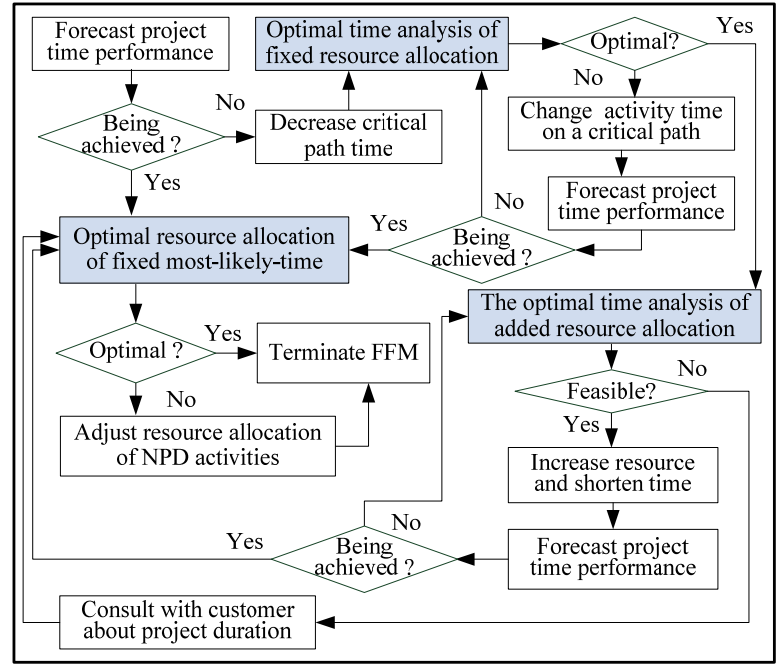

Figure 2. The process architecture of the FFMM

Figure 3 shows the process architecture of the FBMM. In execution phase, when the FBMM detects a NPD activity delays, a project manager must identify the delay problem(s). If the delay is due to resource shortages, the project manager and the NPD engineers re-estimate the quantities of resource requirements and confirm whether these requirements violate resource constraints. If these resource requirements violate the resource constraints, the NPD activity may extend the activity time. If the delay reason is the technology bottleneck, the project manager needs to assess the feasibility of outsourcing the critical technology. If it isn't feasible, the NPD 
project may be terminated. If it is feasible, the project manager re-estimates the activity time and the FBMM forecasts the NPD process time performance. If the process time performance cannot achieve the aim of a NPD project schedule, the FBMM analyzes the feasibility of adjusting the subsequent NPD process using the time estimation of adding resource allocation. If it isn't feasible, the project manager needs to consult with the customer about changing the project time performance. Through employing the FFMM and FBMM, a NPD process can be optimally and quickly modified in the planning phase and execution phase to avoid unexpected delays.

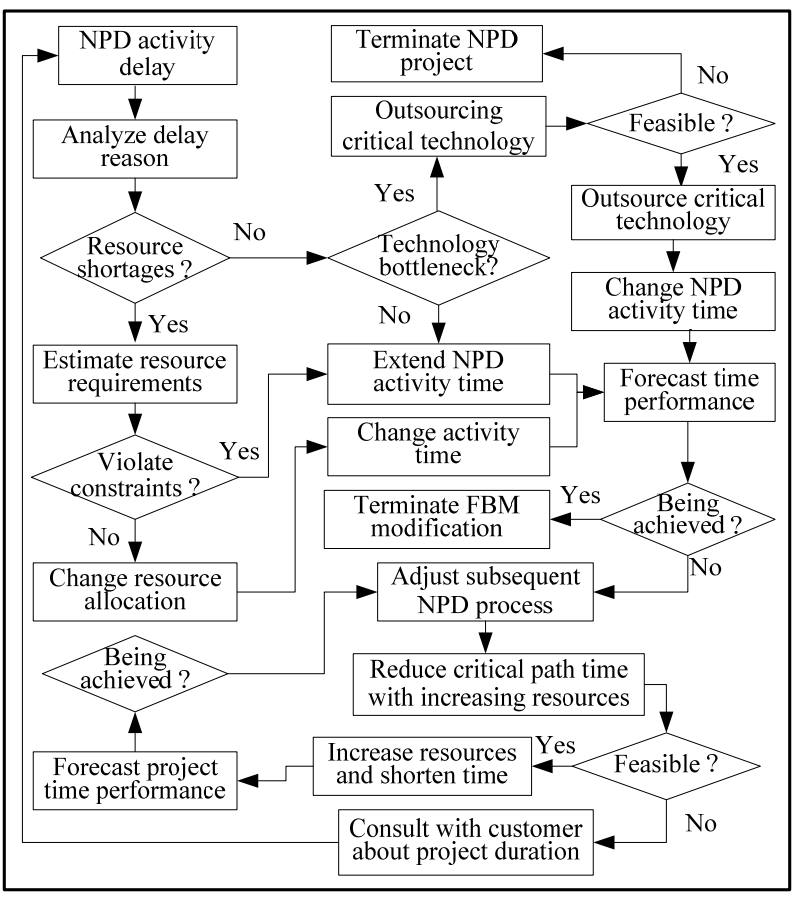

Figure 3. The process architecture of the BMM

\section{Resource Allocation under the Most Likely Completion Time}

This model investigates the feasibility of reducing the NPD resource allocation given the most likely time of project completion. Figure 4 shows the methodological concept for the optimal resource allocation model given the most likely time. In Figure 4, the horizontal axis represents the aggregate resource input. The vertical axis represents the activity time. Points $a, b, c, d$ and $e$ represent benchmarking NPV activities, which are similar to the NPD activity $f$. These benchmarking NPD activities can be obtained from the historical database of the workflow management system by employing the optimal resource allocation model of fixed mostlikely-time. The input-oriented technical efficiency of these benchmarking points is equal to 1 to form the efficiency frontier. The optimal resource allocation model of fixed most-likely-time analyzes the inputoriented technical efficiency of the point $f$ (a new activity $f$ ), denoted by $\theta_{f}$. Because the point $f$ does not locate at the efficiency frontier, the input-oriented technical efficiency is $\theta_{f}<1$. The point $f$ can be projected horizontally onto the point $f^{*}$ on the efficiency frontier. In this instance, the time $\left(t_{f}\right)$ of the activity $f$ remains unchanged and the aggregated resource input is reduced $\Delta f$ when the frontier $\left(f^{*}\right)$ is reached.

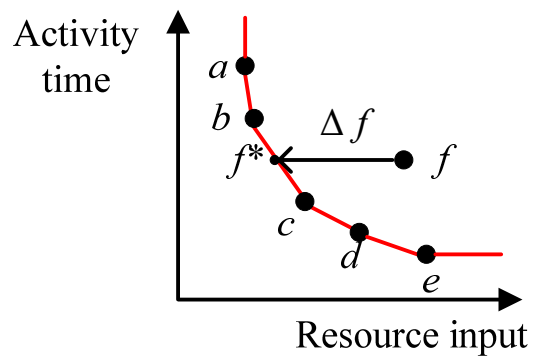

Figure 4. The DEA concept for the optimal resource allocation model of fixed most-likely-time

Resource allocation given the most likely time is represented as

$$
\operatorname{Min} \theta_{f}-\varepsilon\left(\sum_{\forall e \in E} f_{s_{e}}+\sum_{\forall m \in M} h s_{m}\right)
$$

$$
\begin{aligned}
& \text { s.t. } \sum_{j=1}^{n} \lambda_{j} t_{j}=t_{f},(\mathrm{j}=1,2, \ldots, \mathrm{f}, \ldots, \mathrm{n}), \\
& \sum_{j=1}^{n} \lambda_{j} i f_{e j}+f s_{e}=\theta_{f} \text { if } f_{e f} \quad \forall e \in E, \\
& \sum_{j=1}^{n} \lambda_{j} i h_{m j}+h s_{m}=\theta_{f} i h_{m f} \quad \forall m \in M, \\
& \sum_{j=1}^{n} \lambda_{j}=1, \lambda_{j} \geq 0,
\end{aligned}
$$

where

$\theta_{f}$ is the input-technical efficiency of the NPD activity $f$,

$t_{j}$ is the time of the activity $j$,

$t_{f}$ is the most-likely-time of the new activity $f$,

$i f_{e j}$ is the input time of the facility $e$ for the activity $j$,

$i h_{m j}$ is the input time of the human resource $m$ for the activity $j$,

$f s_{e}$ and $h s_{m}$ are slack variables. 
If $\theta_{f}<1$, then it represents the facility and human inputs of the activity $f$ can be reduced without being influencing the most-likely-time. Equation (5) and Equation (6) show the decreasing input quantities of facilities and human resources respectively.

$$
\Delta i f_{e f}=i f_{e f}-\left(\theta_{f}^{*} i f_{e f}-f_{s}^{*}\right)
$$

$$
\Delta i h_{m f}=i h_{m f}-\left(\theta_{f}^{*} i h_{m f}-h s_{m}^{*}\right)
$$

\section{Time Estimation with Fixed Resource Allocation}

This model analyzes the feasibility to shorten a NPD project time without adding resources. Figure 5 displays the methodological concept of time estimation with fixed resource allocation. In Figure 5, points $a, b, c, d$ and $e$ represent the benchmarking activities to form the efficiency frontier. Because the output-oriented technological efficiency of the activity $f\left(\phi_{f}\right)$ is small than 1 , the point $f$ can be projected vertically onto the point $f^{*}$ on the efficiency frontier. In this case, the aggregated resource input maintains the same amount and the activity time can be reduced $\Delta T$.

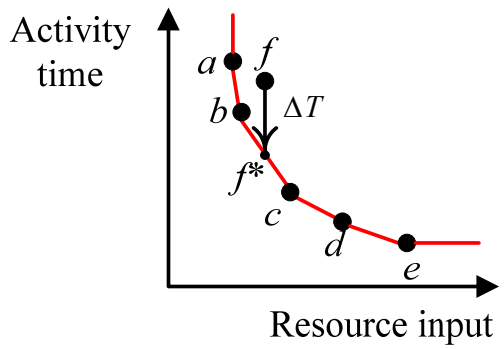

Figure 5. The DEA concept of time estimation with fixed resource allocation

The output-oriented technical efficiency of the activity $f$ is obtained using the following model:

$$
\begin{aligned}
& \operatorname{Min} \phi_{f} \\
& \text { (7) } \\
& \text { s.t. } \sum_{j=1}^{n} \lambda_{j} t_{j} \leq \phi_{f} t_{f},(\mathrm{j}=1,2, \ldots, f, \ldots, n), \\
& \sum_{j=1}^{N} \lambda_{j} i f_{e j} \leq i f_{e f} \quad \forall e \in E, \\
& \sum_{j=1}^{N} \lambda_{j} i h_{m j} \leq i h_{m f} \quad \forall m \in M,
\end{aligned}
$$

$$
\sum_{j=1}^{N} \lambda_{j}=1,
$$

where

$\phi_{f}$ is the output-oriented technical efficiency of the new activity $f$,

$t_{j}$ is the time of the activity $j$,

$t_{f}$ is the most-likely-time of the new activity $f$,

$i f_{e j}$ is the input time of the facility $e$ for the activity $j$,

$i h_{m j}$ is the input time of the human resource $m$ for the activity $j$.

If $\phi_{f}<1$, it shows the time of the activity $f$ can be reduced without adding the resource inputs of the activity $f$. The decreasing time of the activity $f, \Delta \mathrm{T}_{f}$, can be obtained by using Equation (8).

$$
\Delta t_{f}=t_{f}-\mathrm{t}_{f} \times \phi_{f}^{*}
$$

\section{Time Estimation with Added Resource Allocation}

When the objective of the project time performance cannot be achieved by employing the time estimation with fixed resource allocation, this research further analyzes the feasibility of shortening NPD activity times on the critical path through adding activity resources. As shown in Figure 5, the point $f^{*}$ represents the NPD activity $f$ on the critical path. In order to shorten the most likely time of the activity $f$, the point $f^{*}$ moves down along the efficiency frontier and then we can find a benchmarking reference point c. Then, we further analyze the cost-time performance (CTP) of the activity $f$. First, we calculate the decreasing activity time and the increasing resource quantities of the activity $j$, and then the project manager confirms whether the increasing resource quantities violate the resource constraints. If these resource requirements do not violate the resource limits, we can obtain the CTP value using Equation (9).

$c t p_{f}=\frac{\sum_{e \in E} \Delta i f_{e f} \times c r_{e}+\sum_{m \in M} \Delta i h_{m f} \times c h_{m}}{\Delta t_{f}}$ where

$\Delta t_{f}$ is the decreasing time of the activity $f$, $\Delta i f_{e j}$ is the increasing input time of the facility $e$, $\Delta \mathrm{i} h_{m j}$ is the increasing input time of the human resource $m$, 
$\mathrm{c} r r_{e}$ is the input cost of the facility $e$ per unit time,

$c h_{m}$ is the input cost of the human resource $m$ per unit time.

By using the same method, we can get the CTP values of other activities on the critical path and then select the optimal CTP activity and increase its resource allocation. If the CTP value of the activity $f$ is optimal and the project completion time performance cannot be achieved by increasing resources of the activity $f$, we must move down along the efficiency frontier again to look for the next benchmarking point and update its CTP value. Then the project manager selects the best CTP value among the critical-path activities to shorten the most like time of a critical path activity to improve the project time performance.

\section{The Relative Economical Efficiency for NPD Processes within a Product Portfolio}

The completion-and-review phase analyzes the relative economical efficiency on the market for the NPD processes with a product portfolio by employing the DEA approach. The output of the relative economical efficiency under variable returns to scale (VRS) is measured by the net present value (NPV). On the other hand, the inputs of this model include all kinds of facilities and human resources. Each NPD process corresponds to a NPD project. The DEA approach requires the number of NPD projects (i.e., the decision-making units, DMUs) is at least twice times as much as the total numbers of input and output variables. Because the number of NPD projects within a product portfolio may not be sufficient, this research aggregates the individual input quantities into a composite input by using unit costs of resources. We also employ the output oriented VRS-DEA approach to obtain the economical efficiencies for the NPD projects as shown in Equation (10).

$\operatorname{Max} \gamma_{k}$

s.t $\sum_{p=1}^{n} \lambda_{p} n p v_{p}-n p v s \geq \gamma_{k} n p v_{k}, p=1, \Lambda, k, \Lambda, n$

$\sum_{p=1}^{k} \lambda_{p}\left[\left(t i f_{e p} f c_{e}\right)+\left(t i h_{m p} h c_{m}\right)\right] \leq\left[\left(t i f_{e k} f c_{e}\right)+\left(t i h_{m k} h c_{m}\right)\right]$

$\sum_{p=1}^{n} \lambda_{p}=1, \lambda_{p} \geq 0$,

where

$\gamma_{k}$ is the output-oriented relative economical efficiency of the project $k$ with a product portfolio, tif $_{e p}$ is the total input time of the facility $e$ of the project $p$,

$t i h_{m p}$ is the total input time of the human resource $m$ of the project $p$,

$f c_{e}$ is the cost of the facility $e$ per unit time,

$h c_{m}$ is the cost of human resource $m$ per unit time, $n p v_{p}$ is the net present revenue of the NPD project $p$.

From this analytical mode, we can get the outputoriented relative economical efficiency of the $k$ th NPD project with a product portfolio. If $1 / \gamma_{k}<1$, then it represents the $k$ th NPD project should increase the NPV amount $\Delta n p v_{k}$. By using Equation (11), the project manager can acquire the quantitative improvement suggestion.

$\Delta n p v_{k}=\gamma_{k} n p v_{k}-n p v_{k}$

\section{CASE STUDY}

The DEA models are applied to the music mobilephone (MMP) NPD project to demonstrate the methodology at work. According to a NPD project lifecycle, the MMP project evaluation is divided into three phases, i.e., the planning phase, the execution phase and the completion-and-review phase. The following subsections depict the details of implementing the DEA benchmarking methodology for optimizing the MMP development process.

\section{The Planning Phase of a MMP Development Process}

Figure 6 shows the network diagram of the MMP's NPD process. In order to evaluate the completion time performance of a MMP project, the project manager and NPD engineers provide the optimistic, pessimistic and most likely time estimations for each activity within the MMP development process. By using Equation (1) and (2), we can obtain the expected value and variance of each MMP development activity time as shown in Table 1.

In this case, we can understand that the network diagram for the MMP development project has four paths, i.e., A-B-C-E-F-G-M-O, A-D-E-F-G-M-O, AH-I-J-M-O, and A-K-L-M-O. Through employing Equation (3) and Equation (4), this research calculates the expected value and variance of each path time for the MMP development process as shown in Table 2. The longest expected time path AD-E-F-G-M-O is the critical path. Thus, the expected 
MMP project time is approximately the sum of the expected activity time on the critical path, i.e., 197.34 days. Furthermore, the variance of the MMP project time is 56.22 obtained by using Equation (4).

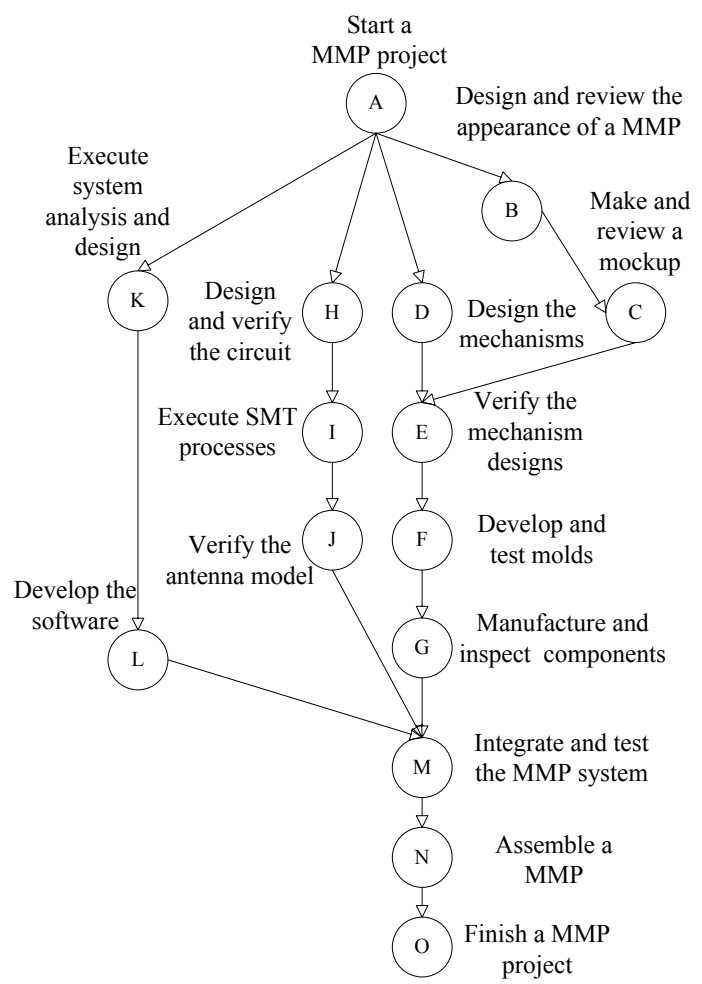

Figure 6. The network diagram of the MMP development process

Table 1. The MMP activity time estimations, expected values and variances

\begin{tabular}{|c|c|c|c|c|c|}
\hline \multirow[t]{2}{*}{ Activity code } & \multicolumn{3}{|c|}{ Time estimates } & \multirow{2}{*}{$\begin{array}{l}\text { Expected } \\
\text { time }\end{array}$} & \multirow{2}{*}{\begin{tabular}{|l} 
Time \\
variance
\end{tabular}} \\
\hline & 0 & $\mathrm{~m}$ & $\mathrm{p}$ & & \\
\hline $\bar{B}$ & 10 & 13 & 15 & 12.83 & 0.69 \\
\hline C & 5 & 5 & 10 & 5.83 & 0.69 \\
\hline $\mathrm{D}$ & 60 & 75 & 90 & 75 & 25 \\
\hline$E$ & $\overline{7}$ & 10 & 14 & 10.17 & 1.36 \\
\hline $\mathrm{F}$ & 50 & 60 & 70 & 60 & 11.11 \\
\hline $\mathrm{G}$ & 7 & 10 & 14 & 10.17 & 1.36 \\
\hline$\overline{\mathrm{H}}$ & 60 & $\overline{75}$ & 90 & 75 & 25 \\
\hline $\mathrm{I}$ & 4 & 4 & 8 & 4.67 & 0.44 \\
\hline $\mathrm{J}$ & 5 & 7 & 10 & 7.17 & 0.69 \\
\hline $\mathrm{K}$ & 12 & 16 & 21 & 16.17 & 2.25 \\
\hline $\bar{L}$ & 50 & 70 & 90 & 70 & 44.44 \\
\hline $\bar{M}$ & 30 & 40 & 55 & 40.83 & 17.36 \\
\hline $\bar{N}$ & 1 & 1 & 2 & 1.17 & 0.03 \\
\hline
\end{tabular}

Table 2. The expected value and variance of each path time for the MMP development process

\begin{tabular}{|c|r|r|}
\hline Path & $\begin{array}{l}\text { Expected } \\
\text { path time }\end{array}$ & Variance of path time \\
\hline A B C E F G M O & 141 & 32.6 \\
\hline A D E F G M O & 197.34 & 56.22 \\
\hline A H I J M O & 128.84 & 43.52 \\
\hline A K L M O & 128.17 & 64.08 \\
\hline
\end{tabular}

When an initial MMP development process planning is completed, the FFMM is animated to estimate the probability that the completion time of this NPD project meets the deadline by employing Equation (5). In this case, the customer requires that the probability of meeting the MMP project time 200 days is 0.98 . However, the aim of the MMP project cannot be achieved because the probability of meeting the deadline is only 0.639 . Owing the mature manufacturing technology and variance of manufacturing time from engineering design changes, this research doesn't analyze the manufacturing activities among the MMP development project for shortening the manufacturing time or decreasing resource allocation.

Firstly, the FFMM analyzes the feasibility of reducing the activity times on the critical path without adding resources by employing the time estimation with fixed resource allocation. Table 3 displays the output-oriented technological efficiency of mechanism design (D), mechanism verification (E), the development and test of the molds (F), and the integration and test of the MMP system (M). Except the activity of mechanism verification, the output oriented technology efficiency of other activities is less than one. Therefore, the FFMM employs Equation (5) to optimally shorten the mostlikely-times of these activities without adding resources (D: 69.25; F: 55.2; and M: 34.8 days). As a result of the most likely time adjustments on the critical path, the FFMM re-evaluates the completion time performance of the MMP by using Equation (3), (4) and (5). The expected project time and the probability of meeting the deadline are adjusted to 190.67 days and 0.972 respectively. Although the probability of meeting the schedule is a significant improvement, it cannot achieve the time-performance objective of the MMP project. Thus, the FFMM further analyzes the feasibility of increasing resources for shortening the critical-path time. Through using the time estimation of adding resource allocation, the FFMM calculates the CTP values of critical-path activities in order to seek the optimum way to decrease the critical-path time. This study uses the development and test of the molds as an example to explain how to gain the CTP value. From 
Table 3, we can find the benchmarking activities that their efficiencies are equal to 1 and their activity times are less than the modified most-likely-time 55.2 days for the development and test of the molds. Their activity times are 51 days, 47 days and 40 days respectively. Owing the input resources of the 51 days are less than 47 days and 40 days, this study selects the 51 days as a reference point. We can use the same method to find the benchmarking reference points of the other critical-path activities. Table 4 displays the time and input resources of the benchmarking reference points of the critical path activities. Then, we can calculate the increasing resource quantities and decreasing days of the critical path activities as shown in Table 4, and the project manager checks whether these resource requirements violate the resource constraints. By employing Equation (10), we can acquire the CTP values of critical-path activities (D: 31913; E: 2450; F: 5160; M:9285). The CTP value of the mechanism verification is the optimal. Hence, the FFMM increases the activity resources of the mechanism verification, and re-assess the completion time performance of the MMP project. The expected project time and the probability of meeting the due day are changed into 185.18 days and 0.976 respectively. This probability cannot satisfy the service level of 0.98 given by the customer. Because the mechanism-verification activity has no other benchmarking activities, the FMM selects the best CTP, i.e., development and test of the molds, among other critical path activities. The probability of meeting the project time 200 days is changed into 0.991 . This probability can satisfy the customer's requirement.

Table 3. The output-oriented technological efficiency of of D, E, F, and $\mathrm{M}$

\begin{tabular}{|c|r|r|r|r|}
\hline Activity code & D & E & F & M \\
\hline Mechanism Engineer & 1700 & 144 & 960 & \\
\hline CAD & 1570 & 128 & 670 & \\
\hline CAE & & & & \\
\hline $\begin{array}{c}\text { Mold flow analysis } \\
\text { application }\end{array}$ & & & 280 & \\
\hline Testing engineer & & & & 560 \\
\hline Activity time & 75 & 10 & 60 & 40 \\
\hline Efficiency & 0.93 & 1 & 0.92 & 0.87 \\
\hline
\end{tabular}

(Resource input unit: hours; activity time unit: days)

Table 4. Increasing resource quantities and decreasing days of the critical-path activities

\begin{tabular}{|c|l|l|r|l|}
\hline Activity code & \multicolumn{1}{l|l|}{ D } & E & F & M \\
\hline Mechanism engineer & 844 & 24 & 60 & \\
\hline CAD & 126 & & 146 & \\
\hline CAE & & 30 & & \\
\hline
\end{tabular}

\begin{tabular}{|c|r|r|r|r|}
\hline $\begin{array}{c}\text { Mold flow analysis } \\
\text { application }\end{array}$ & & & 78 & \\
\hline Testing engineer & & & & 208 \\
\hline Decreasing time & 6.75 & 3 & 4.2 & 2.8 \\
\hline
\end{tabular}

(Resource input unit: hours; activity time unit: days)

The FFMM analyzes the feasibility of decreasing the resource allocations of non-critical path activities under time performance without being influenced. Table 5 shows the input-oriented efficiencies of noncritical path activities. From the analytical results, we can see the efficiencies of the design and verification of the circuit, the verification of the antenna module, and the system analysis and design are less than 1. By employing resource allocation given fixed mostlikely-time, the FFMM adjusts resource allocations of these activities as shown in Table 6. Finally, the FFMM achieves the MMP development process optimization in the planning phase.

Table 5. The input-oriented efficiencies of noncritical path activities

\begin{tabular}{|c|r|r|r|r|r|}
\hline Activity code & B & H & J & K & L \\
\hline ID engineer & 80 & & & & \\
\hline CAD & 72 & & & & \\
\hline $\begin{array}{c}\text { Electronics } \\
\text { engineer }\end{array}$ & & 2472 & & & \\
\hline $\begin{array}{c}\text { Circuit design } \\
\text { software }\end{array}$ & & 2282 & & & \\
\hline $\begin{array}{c}\text { Radio frequency } \\
\text { engineer }\end{array}$ & & & 1300 & & \\
\hline $\begin{array}{c}\text { Radio frequency } \\
\text { lab }\end{array}$ & & & 1150 & & \\
\hline Software engineer & & & & 827 & 1920 \\
\hline $\begin{array}{c}\text { System } \\
\text { development } \\
\text { software }\end{array}$ & & & & & 1820 \\
\hline Activity time & 13 & 75 & 7 & 16 & 70 \\
\hline Efficiency & 1 & 0.92 & 0.95 & 0.87 & 1 \\
\hline
\end{tabular}

(Resource input unit: hours; activity time unit: days)

Table 6. The optimal resource allocations of noncritical path activities

\begin{tabular}{|c|c|c|c|}
\hline Activity code & H & J & K \\
\hline Electronics engineer & 2274 & & \\
\hline Circuit design software & 2099 & & \\
\hline Radio frequency engineer & & 1235 & \\
\hline Radio frequency lab & & 1000 & \\
\hline Software engineer & & & 720 \\
\hline
\end{tabular}

(Resource input unit: hours)

\section{The Execution Phase of a MMP Development Process}


In execution phase, the FBMM detects the delays of development and test of the molds of the MMP project. The project manager decides to maintain the resource allocation and modify the three time estimates for this activity as shown in Table 7. The probability of meeting the deadline is changed into 0.958 . Hence, the FBMM is activated to adjust the following activities of the MMP project. Because the manufacture and inspection of components and the MMP assembly belong to manufacturing activities, the only integration and test of the system can be altered. By increasing the working time 208 hours of testing engineers, the most-likely-time of the integration and test of the system and the probability of meeting the project schedule are changed into 32 days and 0.982 respectively. Thus, this probability can satisfy the customer's requirement.

Table 7. The modified three time estimates for the development and test of the molds

\begin{tabular}{|c|c|c|c|}
\hline Activity code & $\mathrm{o}$ & $\mathrm{m}$ & $\mathrm{p}$ \\
\hline $\mathrm{F}$ & 60 & 68 & 76 \\
\hline
\end{tabular}

(Unit: days)

\section{The Completion-and-review Phase of a MMP Development Process}

This phase evaluates the performance of NPD processes with a product portfolio. This product portfolio includes the music mobile-phone smart mobile-phone, and the multimedia mobile-phone. Because the product lifecycle of most mobile-phones are one year, this research considers the NPV during the first year to be the output value of a mobile-phone, and transforms the resource inputs into the capital input. We use the MMP project as an example. Table 8 shows the input resources of the MMP project and the unit cost of each resource. Then, the capital input of the MMP project can be acquired.

Table 8. The input resources of the MMP project

\begin{tabular}{|c|r|r|}
\hline $\begin{array}{l}\text { The input resources of } \\
\text { the MMP project }\end{array}$ & $\begin{array}{l}\text { Input } \\
\text { time }\end{array}$ & $\begin{array}{l}\text { The cost of } \\
\text { per unit time }\end{array}$ \\
\hline CAD & 2458 & 35 \\
\hline CAE & 158 & 45 \\
\hline $\begin{array}{c}\text { Mold flow analysis } \\
\text { application }\end{array}$ & 202 & 20 \\
\hline Circuit design software & 2099 & 25 \\
\hline Radio frequency lab & 1000 & 100 \\
\hline $\begin{array}{c}\text { System development } \\
\text { software }\end{array}$ & 1820 & 15 \\
\hline ID Engineer & 80 & 210 \\
\hline Mechanism engineer & 2888 & 250 \\
\hline Electronics engineer & 2274 & 250 \\
\hline
\end{tabular}

\begin{tabular}{|c|r|r|}
\hline $\begin{array}{c}\text { Radio frequency } \\
\text { engineer }\end{array}$ & 1235 & 240 \\
\hline Software engineer & 2640 & 250 \\
\hline Testing engineer & 768 & 170 \\
\hline
\end{tabular}

(Resource input unit: hours; the cost of per unit time: NT dollars)

By employing Equation (11) and (13), we can obtain the performance assessment values of these new mobile-phone development projects as shown in Table 9. Because the efficiencies of the MMP project and the smart mobile phone are less than one, this research further analyzes and provides the improvement directions by using Equation (12). From the output-oriented efficiency viewpoint, the multimedia mobile phone and the smart mobile phone should increase NT \$ 32 million and 23 million respectively.

Table 9. The outputs, inputs and efficiencies of all mobile phone development projects within a product portfolio

\begin{tabular}{|c|r|r|r|}
\hline NPD Project & Output & Input & $\begin{array}{l}\text { Performance } \\
\text { evaluation }\end{array}$ \\
\hline $\begin{array}{c}\text { Music } \\
\text { mobile-phone }\end{array}$ & 8600 & 320 & 1 \\
\hline $\begin{array}{c}\text { Multimedia } \\
\text { mobile-phone }\end{array}$ & 5400 & 430 & 0.628 \\
\hline $\begin{array}{c}\text { Smart } \\
\text { mobile-phone }\end{array}$ & 6300 & 601 & 0.733 \\
\hline
\end{tabular}

(Unit: NT\$ 10,000)

\section{DISCUSSION}

Through the case study of this paper, one will realize the NPD planning and management based on subjective judgment can be misleading. Consequently, this paper utilizes the quantifiable approach to benchmark NPD activities and identify the relations between their activity times and resources so as to reasonably adjust the NPD time and resource allocation. From the analytical results of this case study, it shows significant modifications by comparing the managers' judgment and the modularized approach presented in the paper. Moreover, this paper provides the modification mechanisms to assist project managers in planning and controlling a NPD process in planning and execution phases. Finally, in the completion-andreview phase, this research uses the BCC-DEA approach to provide NPD project managers with the valuable improvement suggestions.

\section{CONCLUSION}


The performance evaluation of NPD processes plays a crucial role to benchmark NPD projects within an R\&D company. Current project management solutions, mostly focusing on the planning and completion phases of NPDs, cannot utilize the assessment results to further analyze the feasibility of NPD process improvement and to provide consistent and quantitative NPD decision supports. From the entire process lifecycle point of view, this research develops a novel DEA benchmarking method, which consists of modification mechanisms to optimize NPD processes and avoid unexpected delays. By using the methodology to an actual mobile phone (MMP) development, this research verifies that the approach can be adopted to practical applications with significant benefits to new product development and benchmarking.

\section{ACKNOWLEDGEMENT}

This research is partially supported by the National Science Council and the Industrial Technology Research Institute in Taiwan.

\section{REFERENCES}

1. Anbari, F. (2003). Earned value method and extensions. Project Management Journal, 34, 12-23.

2. Atuahene-Gima, K., Slater, S. F., \& Olson, E. M. (2005). The contingent value of responsive and proactive market orientations for new product program performance. The Journal of Product Innovation Management, 22, 464-482.

3. Azaron, A., Katagiri, H., Sakawa, M., Kato, K., \& Memariani, A. (2006). A multi-objective resource allocation problem in PERT networks. European Journal of Operational Research, 172, 838-854.
4. Bonner, J. M., Ruekert, R. W., \& Walker, O. C. (2002). Upper management control of new product development projects and project performance. The Journal of Product Innovation Management, 19, 233-245.

5. Hillier, S. F., \& Lieberman, J. G. (1995). Introduction to Operations Research, New York, McGraw-Hill.

6. Lipke, W. (2003). Schedule is different. The Measurable News, 31, 4.

7. Jacob, D. (2003). Forecasting project schedule completion with earned value metrics. The Measurable News, 1, 7-9.

8. Ling, Y. Y. F., \& Liu, M. (2004). Using neural network to predict performance of design-build projects in Singapore. Building and Environment, 39, 1263-1274.

9. Pillai, A., Sivathanu, J. A., \& Rao, K. S. (2002). Performance measurement of R\&D projects in a multi-project, concurrent engineering environment. International Journal of Project Management, 20, 165-177.

10. Sicotte, H., \& Langley, A. (2000). Integration mechanisms and R\&D project performance. Journal of Engineering and Technology Management, 17, 1-37.

11. Vandevoorde, S., \& Vanhoucke, M. (2006). A comparison of different project duration forecasting methods using earned value metrics. International Journal of Project Management, 24, 289-302.

12. Yang, K. -K., \& Sum, C. -C. (1997). An evaluation of due date, resource allocation, project release, and activity scheduling rules in a multiproject environment. European Journal of Operational Research, 103, 139-154. 